\title{
Reply to: Conversion after laparoscopic cholecystectomy in England
}

\author{
John Slavin
}

Published online: 23 February 2010

(C) Springer Science+Business Media, LLC 2010

\section{Dear Sir,}

We thank Dr. Hussain et al. [1] for their positive comments on our article [2]. We, of course, agree that all the factors mentioned in their letter are predictors of conversion. Hospital Episode Statistics (HES), on which our study is based, is a national administrative data set that allows us to analyse surgical activity on a national basis. The information contained within HES however is limited, and it is therefore not possible in this kind of study to identify the risk of conversion due to factors such as adhesions and hepatomegaly.

In another study [3] we identified a cohort of patients with presumed bile duct injury following laparoscopic cholecystectomy. These were patients who underwent biliary reconstruction at the time of cholecystectomy or at a later date in the absence of a malignant diagnosis. Using this methodology, we have shown a national bile duct injury rate requiring reconstruction of approximately $0.2 \%$. Interestingly, emergency laparoscopic cholecystectomy and male gender were strongly associated with bile duct injury.

\section{References}

1. Hussain A, Singhal T, Almusawy H, EL-Hasani S (2010) The use of medication after laparoscopic anti-reflux surgery. Surg Endosc. doi:10.1007/s00464-010-0929-x

2. Ballal M, David G, Willmott S, Corless DJ, Deakin M, Slavin JP (2009) Conversion after laparoscopic cholecystectomy in England. Surg Endosc 23:2338-2344

3. Moffat CE, Agarwal S, David G, Durkin DJ, Corless DJ, Slavin JP, Deakin M (2009) Five-year national audit of bile duct injuries following laparoscopic cholecystectomy. Surg Endosc 23 (Suppl 1):200
J. Slavin $(\varangle)$

Department of Surgery, Mid Cheshire Hospitals NHS Trust, Leighton Hospital, Middlewich Road, Crewe CW1 4QJ, UK

e-mail: jpss@doctors.net.uk 